\title{
Creative Self-Efficacy: A New Approach to Social Support and Creativity of SMEs' Owners
}

Submitted 12/12/18, $1^{\text {st }}$ revision $16 / 1 / 19,2^{\text {nd }}$ revision $2 / 2 / 19$, accepted $11 / 2 / 19$

\author{
Sri M. Setyawati ${ }^{1}$, Yusmedi Nurfaizal ${ }^{2}$, C. Dwiatmadja ${ }^{3}$, Ade I. Anggraeni ${ }^{4}$
}

\begin{abstract}
:
Small and Medium Enterprises (SMEs) have a very important role in the economic equality of the community and have a high employment rate.

This study examines the direct and indirect effects of social support and creative self-efficacy on the creativity of SMEs' owners in Banyumas, Indonesia. The sample consists of 119 respondents obtained from Small and Medium business owners in this region. They complement the measure of social support and creative self-efficacy towards the creativity of SME' owners. Structural equation modeling is used to test the proposed relationship between variables using the maximum likelihood estimation of the sample covariance matrix.

The results show that social support, significantly positively influences creative self-efficacy and owner creativity, creative self-efficacy significantly influences the creativity of the owner. The findings also reveal that creative self-efficacy can mediate the relationship of social support with owner creativity. The implications of this study are also discussed.
\end{abstract}

Keywords: Indonesia, social support, creative self-efficacy, owner's creativity, Structural Equation Modeling.

JEL Code: G21, G29.

\footnotetext{
${ }^{1}$ Faculty of Economics and Business, Jenderal Soedirman University, email: smsetya.unsoed@gmail.com

${ }^{2}$ Student at Doctoral of Management Science, Faculty of Economics and Business, Jenderal Soedirman University from STMIK Amikom Purwokerto

${ }^{3}$ Faculty of Economics and Business, Satyawacana University

${ }^{4}$ Faculty of Economics and Business, Jenderal Soedirman University
} 


\section{Introduction}

Positive organizational behavior (Cameron, 2003) has highlighted positive strengths (such as psychological capital, related workflows) of employees, managers, and leaders to improve the optimal work outcomes of work behavior (for example, increased performance, creativity, and innovation). The development of positive psychology has contributed and focused on positive rather than negative things, for example, on psychological capital (Luthans et al., 2007). Psychological capital is an approach to optimize the psychological potential possessed by individuals characterized by: (1) the existence of self-efficacy, namely taking the necessary actions, to achieve success in challenging tasks; (2) positive attribution (optimism); (3) resistance in achieving goals, namely the ability to redefine the road to achieve goals if hope; (4) when facing problems and difficulties, are able to survive and continue (resiliency) in achieving success (Luthans et al., 2007). Osigweh (1989) states that psychology capital is an approach that is characterized by dimensions that can optimize the potential of the individual so that it can help organizational performance.

There is growing empirical evidence that psychological capital has a positive impact on individual attitudes and work behaviors (Luthans et al., 2008; Riswanto et al., 2018). This has been shown in the results of longitudinal studies (Avey et al., 2010; Luthans et al., 2006) and in a field study conducted by Culbertson, Fullagar and Mills (2010). In addition, previous studies have shown that a lack of creativity at all levels can seriously damage the competitiveness of an organization (House, 2004). Studies have clearly demonstrated the importance of creativity for competitive advantage (Amablie, 1996; Argyris and Schön, 1978; Nonaka, 1991; Oldham, 2002). An enhanced understanding of the antecedents of personal and psychological creativity can inform efforts to create and maintain creativity in the organization. This study attempts to focus on the need to integrate PsyCap and the related work flow literature (Gardner et al., 2005, Yammarino et al., 2008) and help understand the process in which this contributes to the results of employee creative work.

Behavior and creativity have focused on the role of positive psychological capital (Avey et al., 2009; Peterson et al., 2009; Sweetman et al., 2011), whether individuals have positive psychological traits certain (for example, creative selfefficacy and optimism) will really show creative behavior. In particular, there is empirical evidence of a positive relationship between emerging positive psychological resources and attitudes and performance in the workplace as a whole (for example, Luthans et al., 2007), their relationship with creative performance has not been directly tested. Therefore, this study addresses and provides empirical evidence to fill the gaps that exist in the theoretical literature.

\section{Literature Review and Development of Hypotheses}


Social cognitive theory shows that individuals are motivated by an assessment of their ability to perform certain tasks (or behaviors) and in the hope that they will produce actions (Bandura, 1986; 1997). Assessment of the abilities, beliefs, and expectations of these individuals can be influenced by their self-efficacy. Individuals who have a high level of self-efficacy can feel more confident and feel difficulties as challenges; These people may also set high goals and try harder to overcome the challenges themselves.

Psychological capital (PsyCap) is operationalized as a core factor consisting of optimism, hope, self efficacy and resilience (Avey et al., 2011). Avey et al. (2011) in a meta-analysis concluded that there was "a positive relationship between PsyCap and desired aryawan attitudes (job satisfaction, organizational commitment, psychological well-being), desired employee behavior (citizenship), and several measures of performance (self, supervisor evaluation, and objective. "They also found a significant negative relationship between PsyCap and unwanted employee attitudes (cynicism, intention to move, work stress, and anxiety) and unwanted employee behavior (deviation). Other studies have shown a positive relationship between PsyCap and well-being, and negative relationships with negative emotional states and fatigue (Luthans et al., 2007; Youssef \& Luthans, 2007).

The construct of creative self-efficacy is expanded from self-efficacy and is defined as trust (or self-confidence) that reflects a person's confidence in his ability to carry out innovation tasks (Nurfaizal et al., 2018; Tierney \& Farmer, 2002; 2011). Individuals with high creative self-efficacy can mobilize motivation, cognitive resources, and actions needed to meet situational demands.

\subsection{The relationship between social support and creative self-efficacy}

Li et al. (2014) have proposed that psychological capital has a state-like nature and is therefore open to development. There is accumulation of evidence to support the positive influence of social support on the components of psychological capital (i.e., self-efficacy, optimism, hope, and resilience). For example, Foote et al. (1990) report a significant relationship between social support and expectations, and social support and self-esteem. In addition, in their study Dougall et al. (2001) reported that social support had a positive influence on optimism. Liu et al. (2013) stated that there is an influence of social support for self-efficacy. Luthans et al. (2008) provide direct evidence that a supportive climate has a positive impact on psychological capital. Studies show that social support has a beneficial effect on psychological well-being (Siedlecki et al., 2014; Nurfaizal et al., 2018). The development and consolidation of perceived self-efficacy is achieved in relation to perceived social support (Schunk and Meece, 2005). Social support is an important aspect to improve self-efficacy, and research has shown that one's self-efficacy has a positive correlation with the social support they get. That is, the more social support persons receive, the higher their self-efficacy (Wang et al., 2015; Khairuunnisa and Supriatna, 2018). Therefore, we propose the following hypothesis: 
Hypothesis 1: Social support will significantly predict psychological capital.

\subsection{The relationship between creative self-efficacy and creativity}

Creative self-efficacy reflects a person's belief in the ability to perform certain tasks in the innovation process (Luthans et al., 2007; Youssef \& Luthans, 2007). Previous research shows that self-efficacy influences employee work performance, wellbeing, work attitudes (Avey et al., 2010; Culbertson et al., 2010), and behaviors related to creative behavior, such as problem solving (Avey et al., 2009; Peterson et al., 2009). Avey et al. (2011) concluded that there was a positive relationship between PsyCap and desired employee behavior and several measures of performance. Because creativity is a risky endeavor (Yuan \& Woodman, 2010), employees face many risks in the creativity process. Someone needs positive psychological capital to overcome uncertainty and failure in the process of creativity. Therefore, the main objective of this study is to expand the literature on creativity by introducing positive psychology theory and empirically testing the relationship between creative self-efficacy and creativity. Therefore, we propose the following hypotheses:

Hypothesis 2: Creative self-efficacy will significantly predict creativity.

Hypothesis 3: Creative self-efficacy will reduce the relationship between social support and creativity. Owners with a high level of social support will have a higher level of creativity if they have high creative self-efficacy.

\subsection{The relationship between social support and creativity}

Contextual characteristics that get attention in the literature, and explain how each characteristic can influence creativity include social support. Previous research provides support for this argument (Amabile \& Gryskiewicz, 1989; Cummings \& Oldham, 1997; Madjar et al., 2002; McGlynn et al., 1982; Torrance, 1965). For example, Amabile et al. (1996) found that individuals in work teams were more creative when their coworkers supported and encouraged. Similarly, Zhou and George (2001) show a positive and significant relationship between employee creativity and peer support and information feedback. However, other studies failed to support this argument. Zhou and George (2001) found an insignificant relationship between employee creativity and the extent to which coworkers provided constructive assistance at work or inaccurate communication. Van Dyne et al. (2002) found an insignificant relationship between creativity and "work tension" (i.e., the extent to which employees debated with members of their working groups and experienced conflicts with them). Finally, Shalley and Oldham (2004) show that individuals who compete with others produce ideas that are higher in overall creativity than those who are not in competition. Therefore, we propose the following hypothesis: 
Hypothesis 4: Social support will significantly predict creativity.

\section{Methodology}

\subsection{Research design and sample}

The study design used a cross-sectional survey conducted in Banyumas Regency, Indonesia, during the period August 2017-November 2017. The sample involved 119 owners of Small and Medium Enterprises (SMEs) located in Banyumas Regency in Indonesia. Structural equation modeling is used to test the proposed relationship between variables using the maximum likelihood estimation of the sample covariance matrix. The criteria used to assess structural models include the goodness of fit index (GFI), comparative improvement index (CFI), Tucker-Lewis index (TLI), and root mean square error approximation (RMSEA). $\chi^{2} / \mathrm{df}<3$, GFI, CFI, and TLI $>0.90$, and RMSEA $<0.08$ indicates the adequacy of the data in the model (Hair et al., 2014). Whereas to find out whether creative self-efficacy can mediate social support with creativity, the Sobel-test analysis is used (Ghozali, 2016).

\subsection{Measurement}

To measure support we use five items of questions from Cheng et al. (2008). Creative self-efficacy is measured by four items with the creative effectiveness scale of Tierney and Farmer (2002). To measure owner creativity, this study uses four items proposed by Vandeleur et al. (2001), Howard et al. (2008), Snider et al. (2016), all individual questions from the three variables above were adjusted. This study adopted seven behaviors, on a scale ranging from 1 (strongly disagree) to 7 (strongly agree).

\subsection{Procedure}

Official permission is obtained from the Department of Industry, Small and Medium Enterprises Banyumas Regency, Indonesia. Information on approval was obtained from each respondent and given a brief explanation of the purpose of the study. The researcher also ensures the confidentiality of information and ensures that information will only be used for academic purposes. There is no time limit for completing the questionnaire to maximize the completion of the questionnaire. Written instructions as well as verbal narratives are provided so that the respondent maximally understands and reduces related ambiguities.

\section{Results}

Table 1 shows the correlation between research variables. The results of the study show that social support variables, creative self-efficacy and creativity have shown significant positive relationships with each other. It has been found further that 
social support is significantly associated with creative self-efficacy and creativity. Likewise creative self-efficacy is significantly related to the creativity of SME owners. In other words, it has been found that SME owners who have a higher level of social support also experience an increase in the level of creative self-efficacy and show greater creativity. Therefore SME owners with higher social support have more creative self-efficacy and higher social support owners and creative selfefficacy are more creative.

Table 1: Correlation matrix between research variables between SME owners $(N=$ 119)

\begin{tabular}{|c|c|c|c|c|}
\hline \multicolumn{2}{|l|}{ Variable } & Social Support & $\begin{array}{l}\text { Creative } \\
\text { Self_efficacy }\end{array}$ & Creativity \\
\hline \multirow[t]{3}{*}{ Social Support } & Pearson Correlation & 1 & $400^{* *}$ & $.424^{* *}$ \\
\hline & Sig. (2-tailed) & & .000 & .000 \\
\hline & $\mathrm{N}$ & 119 & 119 & 119 \\
\hline \multirow[t]{3}{*}{ Creative Self_efficacy } & Pearson Correlation & $400^{* * *}$ & 1 & $.539^{* *}$ \\
\hline & Sig. (2-tailed) & .000 & & .000 \\
\hline & $\mathrm{N}$ & 119 & 119 & 119 \\
\hline \multirow[t]{3}{*}{ Creativity } & Pearson Correlation & $424^{* *}$ & $.539^{* *}$ & 1 \\
\hline & Sig. (2-tailed) & .000 & .000 & \\
\hline & $\mathrm{N}$ & 119 & 119 & 119 \\
\hline
\end{tabular}

Table 2 shows the results of structural equation modeling (using SPSS Amos 21 with the maximum likelihood estimation method) testing the causal model. The results showed that the chi-square X2 produced was 68,787 smaller than the chisquare value of the Table with an error rate of $1 \%$ and the sample size 119 which is 157,799 . This value indicates that the tested model is accepted in good category. The resulting probability value is 0.649 , which is much greater than the cut-of value of 0.05. This value indicates that there is a significant difference between the data covariance matrix and the estimated covariance matrix, so that the model is accepted in the good category. The CMIN/DF value of the full SEM model in this study is 0.930 smaller than the cut-off value which is 2.00 which indicates that the fit between the model and the data, which means the model is accepted in good category. Referring to the results of the goodness of fit test in Table 2, it is known that the GFI value is 0.930 greater than the cut off value which is 0.90 . This value indicates that the suitability level of the weighted proportion of the sample covariance matrix variance explained by the population matrix estimated is in the good category. Furthermore, the full SEMFI model SEM value of this study is 0.901 which is also greater than the cut-off value of 0.90 . This AGFI value indicates that the suitability between the weighted proportion of variance in the sample matrix explained by the estimated population matrix is in the good category. The goodness of fit model test results show that the TLI value is 1.011 greater than the cut off 
value which is 0.95 . The TLI value indicates that the degree of conformity of the incremental index that compares the model with the baseline model is accepted in the good category. The CFI value in this research model is also greater than the cut off value, which is 0.95 . This value indicates that the suitability of the index comparing a model tested against the baseline model is accepted in the good category. The data in Table 2 also shows that the RMSEA value is 0,000 smaller than the cut off value which is 0.08 . This value shows the index accepted by the model which shows a close fit of the degree of freedom model in good category.

Table 2: Summary of Goodness of Fit Test Results

\begin{tabular}{|l|l|l|l|}
\hline Goodness of fit Index & Analysis Results & Cut of Value & Model Evaluation \\
\hline$X^{2}$ Chi-Square & 68.787 & $<164.694$ & Fit \\
\hline Probability & 0.649 & $>0.05$ & Fit \\
\hline CMIN/DF & 0.930 & $<2.00$ & Fit \\
\hline GFI & 0.930 & $>0.90$ & Fit \\
\hline AGFI & 0.901 & $>0.90$ & Fit \\
\hline TLI & 1.011 & $>0.95$ & Fit \\
\hline CFI & 1.000 & $>0.95$ & Fit \\
\hline RMSEA & 0.000 & $<0.08$ & Fit \\
\hline
\end{tabular}

Based on the summary of SEM analysis results in Table 3 it can be seen that the value of critical ratio (CR) for the influence of social support variables for creative self efficacy is 4.057 with a value of P 0.000 , the value of critical ratio (CR) for the influence of social support variable on creativity is 2.044 with $\mathrm{P}$ value 0.041 , the value of critical ratio (CR) for the influence of the creative self efficacy variable on creativity is 2.596 with a $\mathrm{P}$ value of 0.009 , therefore, hypotheses 1,2 and 4 are supported.

Table 3: Standarized regression weight for hypothesis testing

\begin{tabular}{|l|l|l|l|l|}
\hline Causal Relationships & C.R. & P \\
\hline Creative_Self_Efficacy & $<---$ & Social Support & 4.057 & $* * *$ \\
\hline Creativity & $<---$ & Social Support & 2.044 & .041 \\
\hline Creativity & $<---$ & Creative_Self_Efficacy & 2.596 & .009 \\
\hline
\end{tabular}

Referring to the results of the calculation of the Sobel test, it can be seen that the value of $\mathrm{t}$ calculated variable social support for creativity through creative self efficacy is 2.153 greater than the value of t Table (1.980). Thus, hypothesis 3 is supported.

\section{Discussion}

Creativity is the first step in innovation, and innovation is very important for longterm organizational success (Amabile, 1997). Thus, organizations need to utilize and facilitate creativity. This study can help organizations and researchers to identify ways to address this need. This study was designed to assess the role of social 
support and creative self-efficacy related to the creativity of SME owners in Banyumas, Indonesia. It is also intended to analyze the role of creative self-efficacy in mediating the relationship between social support and creativity. The findings show that social support relates to creative self efficacy of SME owners. Previous empirical evidence (Foote et al., 1990; Dougall et al., 2001).

Liu et al. (2013), Luthans et al. (2008), Siedlecki et al. (2014), Schunk and Meece (2005) and Wang et al. (2015) also show that the more social support a person receives, the higher its self-efficacy.

Similarly, it has been found that creative self efficacy positively predicts desired creativity, in addition to creative self efficacy can mediate the relationship between social support and creativity. This is in line with the findings of Avey et al. (2010), Culbertson et al. (2010), Avey et al. (2009), Peterson et al. (2009), Avey et al. (2011) and Yuan \& Woodman, (2010). The results of this study also show that social support is a major predictor of creativity of SMEs' owners. This has extensive support from previous literature (Amabile \& Gryskiewicz, 1989; Cummings \& Oldham, 1997; Madjar et al., 2002; McGlynn et al., 1982; Torrance, 1965. For example, Amabile et al. (1996), Zhou and George (2001) and Shalley and Oldham (1997) have showed the important role of social support.

Figure 1. Structural equation modeling to predict creativity

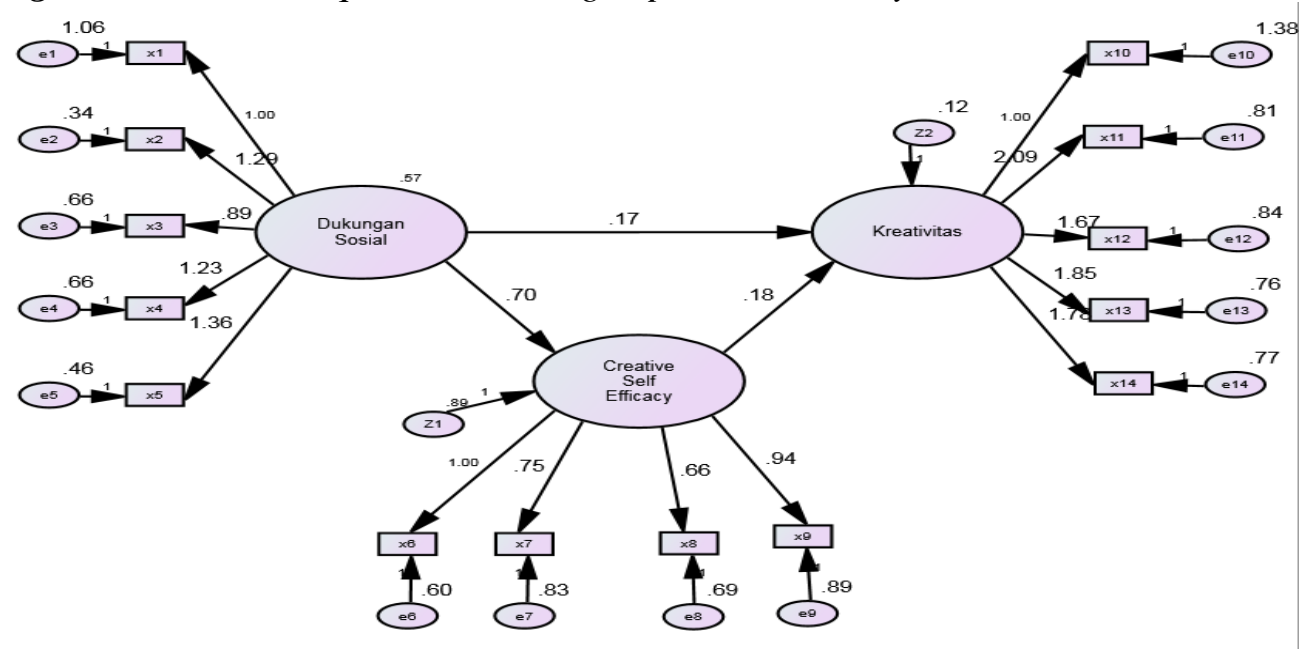

Therefore, this study indirectly reinforces theoretical and empirical evidence that shows that social support and creative self efficacy can help the development of creativity. This is a contribution to the field where empirical studies need to be conducted, especially regarding mediating variables that explain the impact of social support in the results of the creativity of SME owners. 


\section{Conclusion}

The findings of this study indicate that social support and creative self efficacy are predictors of creativity, and also identify the relationship of social support with creativity mediated by creative self efficacy. An additional highlight of this study is that creative self efficacy has a stronger influence than social support for creativity. However, it can be noted that these findings are based on data from samples taken from parts of Indonesia and therefore cannot be generalized widely other than that longitudinal approaches must be used in future research.

\section{Implications}

Related creativity and benefits for the organization in obtaining competitive advantage. We suggest that it is important to recognize that the level of individual creative self-efficacy also plays a role in increasing the positive contribution of social support to creativity. In the context of Small and Medium Enterprises, human resource practitioners can identify and design jobs by optimally promoting social support and creative self-efficacy among SME owners to accelerate their creative production. Industrial psychologists / organizations can design and develop training modules that can encourage creative self efficacy by increasing self-motivation and intrinsic motivation of SME owners.

\section{References:}

Amabile, T.M., Gryskiewicz, N. 1989. The creative environment scales: The work environment inventory. Creativity Research Journal, 2, 231-254.

Amablie, T.M. 1996. Creativity in context: Update to the social psychology of creativity. Boulder: West-view Press.

Argyris, C., Schön, D. 1978. Organizational learning: A theory of action perspective. Reading: Addison Wesley.

Avey, J.B., Luthans, F., Jensen, S.M. 2009. Psychological capital: A positive resource for combating employee stress and turnover. Human Resource Management, 48(5), 677-693.

Avey, J.B., Luthans, F., Youssef, C.M. 2010. The additive value of positive psychological capital in predicting work attitudes and behaviors. Journal of Management, 36(2), 430-452.

Avey, J.B., Luthans, F., Smith, R.M., Palmer, N.F. 2010. Impact of positive psychological capital on employee well-being over time. Journal of Occupational Health Psychology, 15(1), 17-28.

Avey, J.B., Reichard, R.J., Luthans, F., Mhatre, K.H. 2011. Meta-analysis of the impact of positive psychological capital on employee attitudes, behaviors, and performance. Human Resource Development Quarterly, 22(2), 127-152, doi:10.1002/hrdq.20070.

Bandura, A. 1986. Social foundations of thought and action: A social cognitive theory. New Jersey: Prentice-Hall.

Bandura, A. 1997. Self-efficacy: The exercise of control. New York: Freeman.

Cameron, K., Dutton, J., Quinn, R. 2003. Positive Organizational Scholarship. San Francisco, CA: Berrett-Koehler Publishers. 
Culbertson, S.S., Fullagar, C.J., Mills, M.J. 2010. Feeling good and doing great: The relationship between psychological capital and well-Being. Journal of Occupational Health Psychology, 15(4), 421-433.

Dougall, A.L., Hyman, K.B., Hayward, M.C., McFeeley, S., Baum, A. 2001. Optimism and traumatic stress: The importance of social support and coping. Journal of Applied Social. Psychology, 31, 223-245.

Foote, A.W., Piazza, D., Holcombe, J., Paul, P., Daffin, P. 1990. Hope, self-esteem and social support in persons with multiple sclerosis. Journal of Neuroscience Nursing, 22, 155-159.

Gardner, W.L., Avolio, B.J., Luthans, F., May, D.R., Walumbwa, F.O. 2005. Can you see the real me? A self-based model of authentic leader and follower development. The Leadership Quarterly, 16, 343-372.

Ghozali, I. 2016. Aplikasi Analisis Multivariat dengan Program IBM SPSS. Semarang. Penerbit Universitas Diponegoro.

Hair, J.F. 2014. Multivariate Data Analysis, 7th Edition. New York: Prentice Hall International, Inc.

House, R.J. 2004. Preface. In R.J. House, P.J. Hanges, M. Javidan, P.W. Dorfman, V. Gupta (Eds.), Culture, leadership, and organizations: The GLOBE study of 62 societies (pp. xxii-xxviii). Thousand Oaks. Sage.

Howard, T.J., Culley, S.J. Dekoninck, E,A. 2008. Describing the creative design process by the integration of engineering design and cognitive psychology literature. Des Stud. 29(2), 160-180.

Cheng, Y., Liu, C., Mao, C., Qian, J., Liu, K., Ke, G. 2008. Social support plays a role in depression in Parkinson's disease: A cross-section study in a Chinese cohort. Parkinsonism \& Related Disorders, 14, 43-45.

Khairuunnisa, I. \& Supriatna, E. 2018. Analysis of Women's Economic Empowerment in Sukabumi City. Arthatama Journal of Business Management and Accounting, 2(1).

Li, B., Hongyu, M., Yongyu, G., Fuming, X., Feng, Y. \& Zongkui, Z. 2014. Positive Psychological Capital: A New Approach to Social Support and Subjective WellBeing. Social Behavior and Personality, 42(1), 135-144.

Liu, L., Ran, P., Wei, S., Ming, W., Peng, Q., Chunming, L. and Lie, W. 2013. Functional social support, psychological capital, and depressive and anxiety symptoms among people living with HIV/AIDS employed full-time. BMC Psychiatry 2013.

Luthans, F, Avey, J.B., Avolio, B.J., Norman, S.M., Combs, G.M. 2006. Psychological capital development: Toward a micro-intervention. Journal of Organizational Behavior, 27(3), 387-393.

Luthans, F., Norman, S.M., Avolio, B.J., Avey, J.A. 2008. The mediating role of psychological capital in the supportive organizational climate-employee performance relationship. Journal of Organizational Behavior, 29(2), 219-238.

Luthans, F., Youssef, C.M., Avolio, B.J. 2007. Psychological capital. Oxford: Oxford University Press.

Luthans, F., Youssef, C.M. 2007. Emerging positive organizational behavior. Journal of Management, 33, 321-349.

Luthans, F., Avolio, B.J., Avey, J.B., Norman, S.M. 2007. Positive psychological capital: measurement and relationship with performance and satisfaction. Personnel Psychology, 60(3), 541-572.

Madjar, N., Oldham, G.R. \& Pratt, M.G. 2002. There's no place like home? The contributions of work and non-work creativity support to employees' creative performance. Academy of Management Journal, 45, 757-767. 
McGlynn, R.P., Gibbs, M.E., Roberts, S.J. 1982. Effects of cooperative versus competitive set and coaction on creative responding. Journal of Social Psychology, 118, 281282.

Nonaka, I. 1991. The knowledge-creating company. Harvard Business Review, 69, 96-104.

Nurfaizal, Y., Dwiatmadja, C. and Setyawati, S.M. 2018. Psychological Capital as Mediation Between Family Support and Creative Behavior in Handicraft Sector SMEs. International Journal of Entrepreneurship, 22(3).

Oldham, G.R. 2002. Stimulating and supporting creativity in organizations. In S. Jackson, M. Hitt, \& A. DeNisi (Eds.), Managing knowledge for sustained competitive advantage (pp. 243-273), San Francisco: Jossey-Bass.

Oldham, G.R. \& Cummings, A. 1997. Employee creativity: personal and contextual factors at work. Academy of Management Journal, 39(3), 607-634.

Osigweh. 1989. Concept falibility in organizational science. The management rewiew, 14(4), 579-594.

Peterson, S.J., Walumbwa, F.O., Byron, K. \& Myrowitz, J. 2009. CEO positive psychological traits, transformational leadership, and firm performance in hightechnology start-up and established firms. Journal of Management, 35(2), 348-368.

Riswanto, A., Saribanon, E., Gaffar, V. 2018. The importance of the cultural and gender outlook on consumer behavior studies: An Indonesian perspective. Arthatama Journal of Business Management and Accounting, 2(1).

Shalley, C.E., Zhou, I. \& Oldham, G.R. 2004. The effects of personal and contextual characteristics on creativity: where should we go from here. Journal of Management, 30(6), 933-995.

Schunk, D.H. \& Meece, J.L. 2005. Self-Efficacy Development in Adolescences. In T. Urdan \& F. Pajares (Eds.), Self-Efficacy Beliefs of Adolescents, 71-96, Greenwich, CT: Information Age Publishing.

Siedlecki, K.L., Salthouse, T.A., Oishi, S., Jeswani, S. 2014. The relationship between social support and subjective well-being across age. Social Indicators Research. 117, 561576, doi: 10.1007/s11205-013-0361-4.

Snider, C., Dekoninck, E., Culley, S. 2016. Beyond the Concept: Characterisations of LaterStage Creative Behaviour in Design. Res Eng Design, DOI 10,1007/s00163-0160218-3.

Sweetman, D., Luthans, F., Avey, J.B., Luthans, B.C. 2011. Relationship between positive psychological capital and creative performance. Canadian Journal of Administrative Sciences, 28(1), 4-13.

Tierney, P. \& Farmer, S.M. 2002. Creative self-efficacy: its potential antecedents and relationship to creative performance. Academy of Management Journal, 45(6), 1137-1148.

Tierney, P. \& Farmer, S.M. 2011. Creative self-efficacy development and creative performance over time. Journal of Applied Psychology, 96(2), 277-293.

Van Dyne, L., Jehn, K.A. \& Cummings, A. 2002. Differential effects of strain on two forms of work performance. Individual employee sales and creativity. Journal of Organizational Behavior, 23, 57-74.

Vandeleur, S., Ankiewicz, J.P., de Swardt, E.A., Gross, J.E. 2001. Indicators of creativity in a technology class: a case study. South African Journal of Education, 21(4).

Wang, Chun-Mei, Hai-Ying Qu, Hong-Mei Xu. 2015. Relationship between social support and self-efficacy in women psychiatrists. Chinese Nursing Research, 2, 103-106. 
Yammarino, F.J., Dionne, S.D., Schriesheim, C.A., Dansereau, F. 2008. Authentic leadership and positive organizational behavior: a mesomulti-level perspective. The Leadership Quarterly, 19(6), 693-707.

Youssef, C. \& Luthans, F. 2007. Positive organisational behavior in the workplace: The impact of hope, optimism, and resilience. Journal of Management, 33, 774-800, doi:10.1177/014920630 7305562.

Yuan, F.R. \& Woodman, R.W. 2010. Innovative behavior in the workplace: The role of performance and image outcome expectations. Academy of Management Journal, 53(2), 323-342.

Zhou, J. \& George, J.M. 2001. When job dissatisfaction leads to creativity: Encouraging the expression of voice. Academy of Management Journal, 44, 682-696. 